\title{
SOCIETY AFFILIATES
}

A new affiliate status has been created to acknowledge those commercial organizations that support the Society for Computers in Psychology's attempts to encourage further development and use of computers in psychology. Two organizations that contributed financially to the support of the 1982 conference, and thus became its first affiliates, are:

\section{COULBOURN INSTRUMENTS}

and

PSYCHSYSTEMS 